\title{
Micro Foundations for Wage Flexibility: Wage Insurance at the Firm Level*
}

\author{
Ana Rute Cardoso \\ Institute for Economic Analysis, E-08193 Barcelona, Spain \\ anarute.cardoso@iae.csic.es
}

Miguel Portela

University of Minho, PT-4710-057 Braga, Portugal

mangelo@eeg.uminho.pt

\begin{abstract}
To what extent do firms insulate their workers' wages from fluctuations in product markets? Which firm and worker attributes are associated with wage flexibility at the micro level? We first rely on Guiso, Pistaferri and Schivardi (2005) to estimate dynamic models of sales and wages, finding that in Portugal, workers' wages respond to permanent shocks on firm performance, as opposed to transitory shocks. We then explore the factors associated with wage flexibility, finding that collective bargaining and minimum wages are associated with higher wage insurance by the firm, while the threat of firm bankruptcy reduces it. Managers receive less protection against permanent shocks than other workers.
\end{abstract}

Keywords: Wage shocks; risk sharing; rent sharing

JEL classification: $C 33 ; D 21 ; J 33 ; J 41$

\section{Introduction}

The impact of high wage flexibility on reducing economic fluctuations and improving macroeconomic performance has been highlighted in the literature, where wage flexibility has invariably been evaluated as the responsiveness of wages to aggregate conditions, namely the unemployment rate. However, in the terminology of Faggio and Nickell (2005), wage flexibility has two different aspects: the responsiveness of wages to labor market conditions and the responsiveness of wages within a firm to idiosyncratic

\footnotetext{
* We are grateful to Rob Alessie, Dan Hamermesh, Marie-Claire Villeval, and the anonymous referees for valuable comments. We thank Lorenzo Capellari for having provided his presentation to the 5th UK meeting of Stata users on minimum distance estimation. The first author acknowledges the support of the Barcelona GSE Research Network and of the Government of Catalonia. The second author acknowledges financial support from Fundação para a Ciência e a Tecnologia, under grant SFRH/BD/5114/2001. Part of this work was carried out while MP was visiting IZA Bonn, whose support is gratefully acknowledged. We are also thankful to the Ministry of Labor and Social Solidarity for access to data.
}

(C) The editors of the Scandinavian Journal of Economics 2009. Published by Blackwell Publishing, 9600 Garsington Road, Oxford, OX4 2DQ, UK and 350 Main Street, Malden, MA 02148, USA. 
shocks on its productivity or output. They concentrate on the first aspect. The second aspect can be understood as micro foundations for wage flexibility, the issue under analysis in the current study. We focus on Portugal, pointed out as one of the OECD economies with the highest wage flexibility, despite its labor market regulations.

More precisely, we will provide an answer to the questions: What is the responsiveness of wages to shocks on firm output? In other words, to what extent do firms provide wage insurance to their workers, insulating them from fluctuations in product markets? Which firm and worker attributes are associated with a higher degree of wage flexibility at the firm level? A very precise hypothesis has been stated by Faggio and Nickell (2005): national collective bargaining is associated with lower responsiveness of wages to labor market conditions. We will check whether workers covered by national bargaining agreements also see their wages react less to firm-level idiosyncratic shocks than the wages of workers covered by more decentralized agreements. At first sight, this might be expected; however, it is not necessarily the case. Indeed, Teulings (1997) has argued that in a corporatist setting for wage bargaining, firms can delegate the task of adjusting contracts to macro-level shocks onto trade unions, while then promoting adjustments to firm-level idiosyncratic shocks. Also, Cardoso and Portugal (2005) have shown that firms are able to overcome the constraints imposed by collective bargaining by adjusting the actual wage paid on top of the bargained wage. We will also inspect the impact of other labor market regulations, namely the minimum wage, on wage flexibility. Other hypotheses can be derived from the wage insurance literature, which has shown that the share of risk borne by the firm and the worker depends on such factors as: the persistence of the shocks hitting the firm; workers' and firms' preferences, namely their degree of risk aversion; the sensitivity of firm output to worker effort; the likelihood of bankruptcy.

An empirical test on such theories depends crucially on the quality and detail of the available data. We use a longitudinal matched employeremployee dataset of remarkable quality, which matches all the firms and workers in the manufacturing and services private sectors. Given its nature, problems commonly faced by longitudinal datasets, such as panel attrition and under- or over-representation of certain groups, are avoided. Also, measurement errors are reduced due to the contribution of reliability resulting from the legal requirement of data being posted in a visible location within the company.

Guiso, Pistaferri and Schivardi (2005) have devised an empirical strategy for quantifying the impact of temporary and permanent firm-level shocks on wages, which relies on longitudinal matched employer-employee data to estimate dynamic panel data models. We will follow their strategy in order to quantify the wage response on firm-level permanent and transitory 
shocks. We will then explore the forces that shape wage flexibility at the firm level, in particular the role of the institutional setting.

After a brief revision of the literature, Section III describes the institutional framework for wage setting in Portugal, and Section IV describes the data. Sections V to VIII summarize the empirical model and present the results; concluding comments are presented in Section IX.

\section{Wage Insurance in the Previous Literature}

Insurance models can explain why wages are not adjusted as much as predicted by spot market theory, following changes in the demand for firm output. The underlying idea is that firms, being risk-neutral, commit to paying a predefined wage to their risk-averse workers, independently of product market fluctuations. Such strategy is profit-maximizing because risk-averse workers will accept a non-stochastic wage that is lower than the expected value of a stochastic wage. Early models were developed by Baily (1974), Gordon (1974) and Azariadis (1975). Other models predict relatively smaller insurance provision. Gamber (1988), in a two-period model, allows for firm bankruptcy, which constrains the capacity of the firm to provide insurance to its workers, and distinguishes between temporary and permanent shocks. In Gamber's model, real wages react more to permanent than to temporary shocks. In the latter, firms wishing to smooth workers' wages over time can promote a relatively small wage adjustment in the period the shock occurs, deferring the remaining adjustment to the following period.

A central issue that follows concerns the enforceability of insurance contracts. For example, if worker performance is not verifiable, the firm may gain from declaring that it is below its actual level and may renege on the contract, thus paying a wage lower than the insurance wage. Similarly, if worker mobility is allowed, the worker may gain from reneging on the contract and from accepting a better outside offer. Implicit contract theory has established conditions under which it is in the firm's and in the worker's interest to stick to the contract. Basically, workers and firms will respect the contract as long as its long-run gains outweigh the short-term benefit from reneging on it. The insurance wage could therefore fluctuate between the strict level required to prevent the firm from dismissing the worker and, by similar reasoning, the strict level required to prevent the worker from quitting. The latter case holds when contracts are not binding on the worker, whereas the former holds when contracts are not binding on the firm. ${ }^{1}$

\footnotetext{
${ }^{1}$ For an early overview of contract theory, see Rosen (1985). Weiss (1984) has considered the role of mobility costs preventing workers from quitting and thus enabling firms to provide
} 
Empirical studies initially relied on aggregate industry data-e.g. Gamber (1988), Christofides and Oswald (1992) and Blanchflower, Oswald and Sanfey (1996) - progressing to the use of firm-level averages; e.g. Nickell and Wadhwani (1990) and Hildreth and Oswald (1997). Beaudry and DiNardo (1991) use individual worker data, but their indicator of market conditions is computed at the aggregate or industry level. Similarly, Weinberg (2001) uses individual data, but relies on a measure of shocks defined at the industry level to analyze wage and employment fluctuations in response to demand shocks. Devereux (2005) relies upon panel data on workers to quantify the impact of industry-level demand shocks on wages, finding that industry wages respond positively to changes in industry employment. Faggio and Nickel (2005) use worker longitudinal data to quantify the impact on wages of changes in labor market conditions at the regional level. Finally, Guiso et al. (2005) have set a new benchmark on the analysis of this issue: the innovative empirical identification strategy relies on longitudinal matched employer-employee data to estimate dynamic panel data models and quantifies the impact of temporary and permanent firm-level shocks on wages. They found that firms provide full insurance against temporary shocks, while providing only partial insurance against permanent shocks.

The literature on wage insurance is linked to that on rent sharing, having a common aim in particular, to check the relationship between wages and profits (or another indicator of performance). In one case, it is highlighted that firms and workers share risks, while in the other case, they share rents. The theoretical background is different, however. The wage insurance literature, relying mostly on implicit contracts theory, highlights the individual nature of the contract signed between the firm and the worker (as opposed to the emphasis on the firm and union nature of bargaining), the differential risk aversion by workers and firms, and demand shocks at the micro level that translate into idiosyncratic shocks on firm performance (given its idiosyncratic nature, not affecting the whole market, they are the type of risk that the firm can reduce by diversification). In the wage insurance setting, distortions to competitive mechanisms are brought about mainly by incomplete credit and insurance markets. In the rent-sharing literature, distortions to competitive mechanisms are most often seen as a result of worker bargaining power and, less often, as stemming from efficiency wage considerations or frictions in the labor market.

\footnotetext{
wage insurance; Holmstrom (1981) and Thomas and Worrall (1988) model the consequences of the loss of reputation by firms that renege on a contract; in the model by Harris and Holmstrom (1982), firms learn about worker ability and adjust the wage to the outside market to prevent the worker from quitting.
} 
A broader setting would jointly consider the occurrence of different levels of shocks to firm performance (aggregate, industry and firm-level), disentangling whether workers are insulated from each type and, if so, by which mechanisms: national legislation on worker protection, union action through collective bargaining contracts, or firm-level policies. Such analysis could, in particular, address one issue not handled in the settings described. Indeed, wages may be independent of firm performance for two different reasons: either because the labor market is competitive and wages do not depend on idiosyncratic firm shocks, as they are set by aggregate conditions, or, in situations where wages are bargained, because firms offer insurance. Below we will concentrate only on firm idiosyncratic shocks, distinguishing between their temporary or permanent nature to evaluate their impact on workers' wages.

\section{Wage-setting Institutions in Portugal}

The Portuguese labor market is characterized by a high level of employment rigidity and high wage flexibility. In fact, its strict job protection legislation-covering issues such as advance notice required before dismissal, severance pay, and the rules on use of fixed-term or temporary contracts - invariably places the country among OECD economies having the highest employment rigidity; see, for example, OECD (1999). On the contrary, it also ranks among the OECD economies with the highest wage flexibility, since wages are highly responsive to the unemployment rate, despite the regulated framework; see OECD (1992).

Even though union membership has declined, from $61 \%$ in both 1970 and 1980 to $32 \%$ in 1990 , collective bargaining covers almost all of the workforce; see OECD (1994, p. 184). This coverage results from widespread mechanisms of contract extension: most often, employers who subscribe to an agreement apply it to the entire workforce, irrespective of worker union membership status; employer or worker representatives can join an existing agreement, subscribing to a contract they had initially not signed; moreover, the government can impose mandatory extensions of existing contracts, when workers are not covered by a trade union, when one of the parties refuses to negotiate or when negotiation is obstructed in any other way. As a rule, wage negotiations are held yearly, and wage updates take effect in January.

Studies at the micro level have identified sources of wage flexibility under this regulated setting. In particular, Cardoso and Portugal (2005) found that wages set by collective bargaining reflect, to a high extent, the degree of power of the negotiating partners, but subsequent firmspecific arrangements reduce the returns to union power, adjusting wages to the conditions that prevail at the micro level. Also, Cardoso (1999) 
found that the returns to various worker attributes vary widely across firms.

Note therefore that both the theoretical underpinnings of wage insurance and the empirical evidence highlight the firm as a relevant level of analysis to discuss the protection of workers' wages against market fluctuations.

\section{The Dataset}

Quadros de Pessoal is a matched employer-employee dataset gathered by the Portuguese Ministry of Employment, based on written inquiry that every company with wage-earners is legally obliged to complete. Public administration and domestic service are not covered, and the coverage of agriculture is low, given its low share of wage-earners. For the remaining sectors, however, the mandatory nature of the survey leads to an extremely high response rate. Each year, around two million workers and 100,000 to 200,000 companies are covered. Data from 1991 to 2000 are used.

Reported data cover the firm and all workers engaged in the firm during a reference week (whether wage-earner, unpaid family member or owner working in the firm). Reported variables include the firm's location, industry, employment, sales volume, ownership structure, and date of creation, as well as the worker's gender, schooling, age, occupation, seniority, wage, duration of work, and collective bargaining contract.

A worker identification code, based on a transformation of the social security number, enables tracking him/her over time. Extensive checks have been performed to guarantee the accuracy of the data, using gender, date of birth and highest schooling level achieved. A firm identification code enables tracking over time. Based in particular on the location of the firm and its official identification codes, extensive controls are implemented by the data-gathering agency to guarantee that a firm is not later assigned a different number.

Details on the construction of the database, sample sizes and descriptive statistics are presented in the Appendix.

\section{Firm Performance}

We adhere to the intuition behind Guiso et al. (2005). The procedure is described as retrieving consistent estimates of residuals from wage regression, and similarly from firm performance. Given the set of controls included in each regression, the residuals capture idiosyncratic shocks on workers' wages and firm performance. We then make use of both residuals, and regress idiosyncratic wage shocks on idiosyncratic firm performance shocks, evaluating the level of insurance provided by the firm to both 
temporary and permanent shocks. Finally, we check for heterogeneity in the degree of wage insurance provided, according to firm and worker attributes.

What accomplishments does this empirical method bring relative to less complex methods previously used in the literature? Mainly, it enables analyzing the provision of wage insurance at the firm level (against idiosyncratic shocks), distinguishing between the impact of shocks with different degrees of persistence (temporary versus permanent).

Based on the specification used by Guiso et al. (2005), firm performance is modeled as

$$
\text { sales }_{j t}=\gamma_{t}+\text { ssales }_{j, t-1}+X_{j t}^{\prime} \Gamma+\eta_{j}+\epsilon_{j t},
$$

where sales $_{j t}$ is the logarithm of sales of firm $j$ in period $t ; X_{j t}$ is a vector of firm characteristics that includes a set of industry and location dummies; $\gamma_{t}$ represents period $t$-specific constant; $\rho$ and $\Gamma$ are parameters to be estimated; $\eta_{j}$ is the firm-specific effect; and $\epsilon_{j t}$ is the remaining component of the error term.

A major issue concerns the empirical measurement of fluctuations in product markets. The shock affecting the firm has been defined using industry output price (see Gamber, 1988; Christofides and Oswald, 1992), industry profit (Christofides and Oswald, 1992; Blanchflower et al., 1996), and firm profits, in studies relying on wage data also aggregated for the firm level (Nickell and Wadhwani, 1990; Hildreth and Oswald, 1997). Abowd and Lemieux (1993) rely on a set of assumptions to compute firm-level quasi-rents per worker (average value-added per worker evaluated at the workers' alternative wage), and use the price of exports and imports at the industry level to instrument it. In a similar vein, Abowd and Allain (1996) compute firm-level quasi-rents, but allow for variation on their impact on wages, depending on the size of the rents and on industry product market conditions. Kramarz (2003) also uses US manufacturing export prices to instrument firm-level quasi-rents, further allowing firm-level imports to have a direct impact on wages (justified by their influence on worker and firm bargaining powers). Guiso et al. (2005) use value-added, arguing that it is the variable directly subject to stochastic fluctuations, as being more reliable than profit. A similar option was taken by Estevão and Tevlin (2003), who nevertheless used industry data. Holzer and Montgomery (1993) used firm sales, with wages averaged for the firm level. We use sales as our indicator of firm performance, arguing that it captures demand uncertainty, as shocks in product demand are directly reflected in changes in sales. Given fluctuations in demand, output could remain unchanged if prices would adjust fully and instantaneously; however, since that is not the case, output undergoes fluctuations (Baily, 1974). Sales were deflated using the GDP deflator. 
Table 1. Sales regression

\begin{tabular}{lrr}
\hline Variable & \multicolumn{3}{c}{ Estimate } \\
\hline Log sales at $t-1$ & 0.47 & $(0.022)$ \\
Region dummies & 8.53 & {$[0.074]$} \\
Industry dummies & 72.54 & {$[0.000]$} \\
Year dummies & 151.30 & {$[0.000]$} \\
Sargan & 37.10 & {$[0.093]$} \\
Sargan d.f. & 27.00 & \\
AR(1) & -21.41 & {$[0.000]$} \\
AR(2) & 5.24 & {$[0.000]$} \\
AR(3) & 0.72 & {$[0.473]$} \\
AR(4) & -0.83 & {$[0.405]$} \\
AR(5) & -0.15 & {$[0.879]$} \\
AR(6) & 0.67 & {$[0.506]$} \\
AR(7) & -0.67 & {$[0.501]$} \\
Observations & & 94,365 \\
Firms & & 17,097 \\
\end{tabular}

Notes: The regression has been estimated by the first-differenced GMM procedure discussed in Arellano and Bond (1991). The instruments are discussed in the text. The dependent variable is log real sales. Robust standard errors reported in parentheses; $p$-values in square brackets. For region, industry and year dummies, the joint $F$-statistic is reported. Sargan d.f. stands for degrees of freedom of the Sargan test. AR shows the test for serial correlation in the first-differenced residuals.

Estimation of equation (1) by ordinary least squares (OLS) or the usual panel models, fixed or random effects, is inconsistent in the presence of the lagged dependent variable, since, by definition, sales $_{j, t-1}$ is correlated with $\eta_{j}$. We follow Arellano and Bond (1991), taking first differences to eliminate the fixed effect, and then estimating equation (1) using a generalized method of moments (GMM) procedure. The set of instruments includes sales ${ }_{j, t-3}$ and earlier levels of this variable. The remaining regressors are treated as exogenous, and introduced in levels as instruments. The results for the one-step GMM estimation procedure are reported in Table 1.

The use of this method calls for some discussion. This solution has poor finite sample properties concerning bias and precision when the available instruments are weak. Blundell and Bond (1998) show that the solution of Arellano and Bond (1991) has a large downward bias when the time series are persistent and the number of periods is small, and argue for the implementation of a system GMM estimation, for first-differences and levels. In our case, this solution is not feasible given the structure of the error component $\epsilon_{j t}$, assumed later. ${ }^{2}$

\footnotetext{
${ }^{2}$ In Section VII we define $\epsilon_{j t}=\zeta_{j t}+\tilde{\nu}_{j t}-\theta \tilde{\nu}_{j, t-1}$ and $\zeta_{j t}=\zeta_{j, t-1}+\tilde{u}_{j t}$, which implies that $\operatorname{Cov}\left(\epsilon_{j t}, \Delta \epsilon_{j, t-\tau}\right) \neq 0$. This renders infeasible the implementation of the system GMM estimation. We thank Rob Alessie for the thorough discussion on the estimation alternatives.
} 
Table 2. Firms' autocovariances

\begin{tabular}{lcc}
\hline$\tau$ & $E\left(\Delta \epsilon_{j t}, \Delta \epsilon_{j, t-\tau}\right)$ & Standard error \\
\hline 0 & 0.7795 & 0.0151 \\
1 & -0.3096 & 0.0080 \\
2 & -0.0653 & 0.0103 \\
3 & 0.0031 & 0.0076 \\
4 & 0.0083 & 0.0073 \\
5 & -0.0051 & 0.0070 \\
6 & -0.0020 & 0.0067 \\
7 & -0.0009 & 0.0067 \\
\hline
\end{tabular}

Note: The autocovariances are computed using all years pooled.

The persistence of sales over time is represented by a coefficient on lagged sales of 0.47 . Our results indicate that industry dummies are jointly significant, just as time dummies and region dummies. According to the Sargan test, we do not reject the validity of our instruments at the $1 \%$ and $5 \%$ levels. The serial correlation in the first-differenced residuals indicates that we should be using lagged levels of sales dated $t-3$ and earlier, as we do.

In Table 2 we report the autocovariance structure for $\Delta \epsilon_{j t}$. The results confirm our choice of instruments. After two lags, the covariance of firstdifferenced residuals is statistically insignificant. These results are of particular interest for specification of the structure of the error term, which will take place in Section VII.

\section{Worker Earnings}

Workers' wages are specified as

$$
\text { wage }_{i j t}=K_{i j t}^{\prime} \Phi+\varphi_{i}+\alpha P_{j t}+\beta T_{j t}+\psi_{i j t},
$$

where wage $_{i j t}$ stands for the logarithm of monthly wage of worker $i$ engaged in firm $j$ in period $t ; K$ includes industry, region and year dummies, as well as age and age-squared. The first component of the error term is the worker-specific effect, $\varphi_{i}$. Following Guiso et al. (2005), we include in the wage regression the permanent and transitory components of firm-specific shock, $P_{j t}$ and $T_{j t}$, respectively, to be further explained in Section VII. The parameters $\alpha$ and $\beta$ capture the impact of these shocks on wages. Finally, $\psi_{i j t}$ is the remaining component of the error term not captured by the worker-specific effect or the firm specificities.

To replicate Guiso et al.'s (2005) strategy for identifying $\alpha$ and $\beta$, we multiply equation (2) by $(1-\rho L)$, where $L$ is the lag operator. The 
Table 3. Wage regression

\begin{tabular}{|c|c|c|}
\hline \multirow{2}{*}{$\begin{array}{l}\text { Variable } \\
\text { Log wage at } t-1\end{array}$} & \multicolumn{2}{|c|}{ Estimate } \\
\hline & 0.69 & $(0.083)$ \\
\hline Region dummies & 13.11 & {$[0.108]$} \\
\hline Industry dummies & 24.54 & {$[0.220]$} \\
\hline Year dummies & 126.50 & {$[0.000]$} \\
\hline Sargan & 27.53 & {$[0.121]$} \\
\hline Sargan d.f. & 20.00 & \\
\hline $\operatorname{AR}(1)$ & -10.85 & {$[0.000]$} \\
\hline $\mathrm{AR}(2)$ & 5.18 & {$[0.000]$} \\
\hline $\operatorname{AR}(3)$ & -1.84 & {$[0.066]$} \\
\hline $\operatorname{AR}(4)$ & 1.75 & {$[0.081]$} \\
\hline $\mathrm{AR}(5)$ & -0.65 & {$[0.515]$} \\
\hline $\mathrm{AR}(6)$ & 0.61 & {$[0.544]$} \\
\hline $\operatorname{AR}(7)$ & -1.21 & {$[0.223]$} \\
\hline Observations & \multirow{2}{*}{\multicolumn{2}{|c|}{$\begin{array}{r}98,655 \\
30,657\end{array}$}} \\
\hline Individuals & & \\
\hline
\end{tabular}

Note: The dependent variable is log real monthly wage; see the notes to Table 1 .

transformed wage equation is defined as

$$
\text { wage }_{i j t}=\rho \text { wage }_{i j, t-1}+(1-\rho L) K_{i j t}^{\prime} \Phi+(1-\rho L)\left(\varphi_{i}+\alpha P_{j t}+\beta T_{j t}+\psi_{i j t}\right) .
$$

The direct implication is that we introduce state dependence on wages in the equation to be estimated. The presence of the lagged dependent variable on the RHS as a result of this transformation brings about an endogeneity problem. In order to solve this issue, and, as in the case of equation (1), we use the Arellano-Bond first-differenced GMM procedure to obtain consistent estimates.

In the current section we concentrate on estimation and analysis of the first-differenced composite error term $\Delta \omega_{i j t}$ associated with the transformed wage equation, and delay to Section VII further analysis of the different components. $^{3}$

We use levels of wage lagged four periods and earlier as instruments for first-differenced equations. The remaining regressors are assumed exogenous and introduced in levels. The results for the one-step first-differenced GMM estimation are reported in Table $3 .{ }^{4}$

\footnotetext{
${ }^{3}$ After we transform equation (2), the composite error term is defined as $\omega_{i j t}=(1-\rho L) \times$ $\left(\varphi_{i}+\alpha P_{j t}+\beta T_{j t}+\psi_{i j t}\right)$.

${ }^{4}$ We have considered each employment spell as a pair worker-firm, since we are interested in the provision of wage insurance by a given firm, and not the overall insurance the worker may enjoy when switching firms.
} 
Table 4. Workers' autocovariances

\begin{tabular}{lcc}
\hline$\tau$ & $E\left(\Delta \omega_{j t}, \Delta \omega_{j, t-\tau}\right)$ & Standard error \\
\hline 0 & 0.0536 & 0.0012 \\
1 & -0.0253 & 0.0008 \\
2 & -0.0034 & 0.0009 \\
3 & -0.0009 & 0.0007 \\
4 & 0.0005 & 0.0006 \\
5 & -0.0001 & 0.0008 \\
6 & 0.0010 & 0.0010 \\
7 & -0.0017 & 0.0014 \\
\hline
\end{tabular}

Notes: The autocovariances are computed using all years pooled. $\Delta \omega_{i j t}$ is the first-differenced composite residual from equation (2).

The coefficient on lagged wage is 0.69 , indicating higher persistence than for sales. Industry dummies are not jointly significant, while region dummies are marginally insignificant at the $10 \%$ level. The test for overidentifying restrictions does not reject our instruments. Table 4 reports the covariance structure of first-differenced residuals associated with equation (2), $\Delta \omega_{i j t}$. First-differencing implies that $\Delta \omega_{i j t}$ lacks $\varphi_{i}$, i.e. it is defined only as a function of the remaining three components of the error term in equation (2). The results support our choice of instruments in Table 3.

\section{Insurance Provision by the Firm}

To quantify the insurance provided by firms to their workers, we need first to estimate the sensitivity parameters, $\alpha$ and $\beta$, and then to estimate the different variance components of the error terms associated with equations (1) and (2). Throughout the section, we borrow the formulation and estimation strategy proposed by Guiso et al. (2005), adjusting for the specificities of our analysis. The main findings are reported in Table 5.

We start by showing in Panel A the covariance structures in the matched sample of firms and workers, which contains 71,585 observations. The first two columns report results similar to those shown in Tables 2 and 4. The last column shows that the covariance between worker and firm lagged shocks is positive and significant, which is a first indication that firms do not provide full insurance to their workers.

To assess insurance within the firm, we now focus our attention on the relation between changes in workers' residuals, $\Delta \omega_{i j t}$, and changes in firm residuals, $\Delta \epsilon_{j t}$. The firm error term, $\epsilon_{j t}$, is formulated as the sum of two components: a random walk and an $\mathrm{MA}(1)$, such that $\epsilon_{j t}=\zeta_{j t}+\tilde{\nu}_{j t}-\theta \tilde{\nu}_{j, t-1}$, 
Table 5. Testing for insurance

\begin{tabular}{lccc}
\hline Panel A. Covariances & & \\
\hline$\tau$ & $E\left(\Delta \omega_{j t}, \Delta \omega_{j, t-\tau}\right)$ & $E\left(\Delta \epsilon_{j t}, \Delta \epsilon_{j, t-\tau}\right)$ & $E\left(\Delta \omega_{j t}, \Delta \epsilon_{j, t-\tau}\right)$ \\
\hline 0 & 0.0545 & 0.7174 & -0.0012 \\
& $(0.0014)$ & $(0.0265)$ & $(0.0010)$ \\
1 & -0.0256 & -0.2912 & 0.0035 \\
& $(0.0009)$ & $(0.0143)$ & $(0.0010)$
\end{tabular}

Panel B. Sensitivity to permanent and transitory shocks

\begin{tabular}{lcc}
\hline & Permanent shock & Transitory shock \\
\hline Sensitivity & 0.0924 & -0.0011 \\
& $(0.0446)$ & $(0.0019)$ \\
Observations & 25,667 & 55,077 \\
$J$-test & {$[0.5405]$} & {$[0.1919]$} \\
$F$-test & {$[0.0019]$} & {$[0.0000]$} \\
Exogeneity test & {$[0.0422]$} & \\
\hline
\end{tabular}

Panel C. Variance components and insurance coverage

\begin{tabular}{lccc}
\hline & Firm & & Worker \\
\hline$\sigma_{\tilde{u}}^{2}$ & 0.1325 & $\sigma_{\xi}^{2}$ & 0.0168 \\
\multirow{2}{*}{$\sigma_{\tilde{v}}^{2}$} & $(0.0203)$ & $\sigma_{\mu}^{2}$ & $(0.0058)$ \\
& 0.3667 & & 0.0058 \\
$\theta$ & $(0.0323)$ & $\lambda$ & $(0.0113)$ \\
\multirow{2}{*}{ Ratio } & -0.1775 & & -0.2155 \\
& $(0.0394)$ & & $(0.0281)$ \\
\hline
\end{tabular}

Notes: The covariances are computed for the matched sample, and pooling all years. The estimation procedure and instruments used in Panel B are explained in the text. The $F$-test refers to the first-stage regression. Standard errors are reported in parentheses; $p$-values in square brackets. The ratio is defined in the text.

where $\zeta_{j t}=\zeta_{j, t-1}+\tilde{u}_{j t}$. By assuming that $E\left(\tilde{u}_{j t}^{2}\right)=\sigma_{\tilde{u}}^{2}, E\left(\tilde{\nu}_{j t}^{2}\right)=\sigma_{\tilde{\nu}}^{2}$ for all $t, E\left(\tilde{\nu}_{j s} \tilde{\nu}_{j t}\right)=E\left(\tilde{u}_{j s} \tilde{u}_{j t}\right)=0$ for $s \neq t$, and $E\left(\tilde{\nu}_{j s} \tilde{u}_{j t}\right)=0$ for all $s$ and $t$, we expect that after two periods the autocovariance of $\Delta \epsilon_{j t}$ goes to zero. Empirically, Table 2 gives support to this specification, since we observe that autocovariances are zero for lags above two, and non-zero for two or fewer lags.

The permanent and transitory shocks, $P_{j t}$ and $T_{j t}$, respectively, included in equation (2) can now be defined. By modeling the firm residual $\epsilon_{j t}$ as defined above, we allow for both permanent and transitory shocks on firm performance. Rewriting equation (1) allows us to formulate

$$
\text { sales }_{j t}=(1-\rho L)^{-1}\left(\gamma_{t}+X_{j t}^{\prime} \Gamma+\eta_{j}\right)+(1-\rho L)^{-1} \epsilon_{j t} .
$$

The first element on the RHS of this equation represents a deterministic component, while the second element is $(1-\rho L)^{-1} \epsilon_{j t}=P_{j t}+T_{j t}$. As

(C) The editors of the Scandinavian Journal of Economics 2009. 
derived by Guiso et al. (2005), the following expressions model the two shock components:

$P_{j t}=(1-\rho L)^{-1} \zeta_{j t} \quad$ and $\quad T_{j t}=(1-\rho L)^{-1}\left((1-\theta L) \tilde{v}_{j t}-(1-\rho)^{-1} \rho \tilde{u}_{j t}\right)$.

Although our results on autocovariances for $\Delta \epsilon_{j t}$ are not too different from Guiso et al. and support the structure adopted for the error term $\epsilon_{j t}$, our findings for the autocovariances of $\Delta \omega_{i j t}$, Table 4 , do not match theirs. Particularly, they find evidence consistent with an MA(3) process for $\Delta \omega_{i j t}$, while our results indicate that the covariances of $\Delta \omega_{i j t}$ are not statistically different from zero after two periods. However, the results we report in Table 3 indicate that (i) the first-differenced residuals in the wage regression can be correlated three periods apart, and (ii) the use of levels of wages lagged four periods and earlier as instruments is validated by the Sargan overidentification test. Combining these pieces of evidence, we follow Guiso et al., and define the last component of the error term in equation (2) as $\psi_{i j t}=\vartheta_{i j t}+\xi_{i j t}-\lambda \xi_{i j, t-1}$, with $\vartheta_{i j t}=\vartheta_{i j, t-1}+\mu_{i j t}$.

At the core of the estimation strategy lies an instrumental variables (IV) regression, whose specific instruments allow for the identification of the parameters of interest, i.e. $\alpha$, the sensitivity of wages to permanent shocks, and $\beta$, the sensitivity of wages to transitory shocks. In both cases, the dependent variable is $\Delta \omega_{i j t}$, and the explanatory variable is $\Delta \epsilon_{j t}$. Consistent estimates of these variables are obtained from sales and wage regressions presented in Tables 1 and 3, respectively. Guiso et al. (2005) show that $\left(\sum_{\tau=-2}^{2} \Delta \epsilon_{j, t+\tau}\right)^{k}$, with $k \geq 1$, is a valid set of instruments to estimate $\alpha$, while the estimation of $\beta$ can be based on the instruments $\left(\Delta \epsilon_{j, t+1}\right)^{m}$, with $m \geq 1$.

To estimate both $\alpha$ and $\beta$ we have used the feasible efficient GMM procedure, controlling for error correlation within firms. ${ }^{5}$ In each regression the specific instruments are defined for $k=m=1, \ldots, 9$. For both regressions, a likelihood-ratio test rejects the null that the extra powers of the instruments are redundant. ${ }^{6}$ The overidentifying restriction tests do not reject the validity of instruments used in both regressions, and from the $F$-test we conclude that the instruments used in each regression are jointly significant. Finally, we performed the exogeneity test for $\Delta \epsilon_{j t}$ based on

\footnotetext{
${ }^{5}$ In the permanent shock regression we clearly reject the null hypothesis of homoskedastic error terms, which justifies the use of GMM. For example, the Pagan and Hall test discussed in Baum, Schaffer and Stillman (2003) has a $p$-value of 0.0148. For the transitory shock the evidence on heteroskedasticity is mixed. However, since our sample is large enough for asymptotic results to be valid, and given that IV gives inconsistent inference results if errors are in fact heteroskedastic, we adopted a conservative strategy and also implemented the GMM procedure in this case. The following conclusions on transitory shocks are not changed if we use generalized IV instead of GMM.

${ }^{6}$ The $p$-value of the tests is always below 0.001 .
} 
the difference in the Hansen-Sargan statistic between a model where it is assumed exogenous and our alternative model where we take it as endogenous. The test rejects the null that $\Delta \epsilon_{j t}$ is exogenous. This result implies that we also reject the equality between the sensitivity to both types of shocks, in line with Guiso et al. (2005).

We conclude from Panel B that workers' wages are not sensitive to transitory shocks on firm performance, but they respond to firm permanent shocks. The elasticity of wages to permanent shocks on firm performance is 0.09 (compared with 0.07 in Guiso et al. for Italy).

Following the evidence provided by Altonji and Segal (1996), we estimated the different variance components using equally-weighted minimum distance. Panel $\mathrm{C}$ reports the results. We can define the two variances associated with the shocks to sales as $\sigma_{u}^{2}=\sigma_{\tilde{u}}^{2} /(1-\rho)^{2}$ and $\sigma_{v}^{2}=\left(1+\theta^{2}\right) \sigma_{\tilde{v}}^{2}+(\rho /(1-\rho))^{2} \sigma_{\tilde{u}}^{2}$. These are the variances of the permanent shock and the transitory shock, respectively. We estimate that $\sigma_{u}^{2}$ is 0.477 , and $\sigma_{v}^{2}$ is 0.485 , which amounts to a considerable variability. The moving average coefficient is about -0.18 . All three estimates are statistically significant. For workers, the variance of transitory shocks, $\sigma_{\xi}^{2}$, is 0.0168 , while the variance of permanent shocks, $\sigma_{\mu}^{2}$, is approximately 0.01 , but statistically insignificant. The moving average parameter estimate is -0.22 , and significant. These results are consistent with our analysis from Panel B. Our results also show that the different variances are considerably higher for firms than for workers. All of our estimated variances are considerably larger than those found for Italy by Guiso et al., just like the absolute value of the moving-average parameters. This can possibly reflect the higher wage flexibility in the Portuguese labor market.

To compute the portion of wage variability that can be attributed to firm shock, the ratio $\sqrt{E\left\{\left[\left(\Delta \omega_{i j t}\right)^{2}\right] \mid j\right\}} / \sqrt{E\left[\left(\Delta \omega_{i j t}\right)^{2}\right]}$ is defined. We conclude that approximately $30 \%$ of the total variability in wages can be explained by firm-specific risk. For the Italian labor market, Guiso et al. conclude that this ratio is about $15 \%$. Combining the evidence gathered thus far, we conclude that Portuguese firms provide less insurance to their workers, when compared to Italian firms, a result in line with the high wage flexibility pointed out by studies on Portugal.

\section{Forces Shaping Wage Flexibility at the Firm Level}

We now turn to the analysis of heterogeneity in insurance provision by firms. We consider different factors identified in the theoretical literature as shaping wage flexibility at the firm level. First of all, firms may be subject to institutional constraints. As argued by Faggio and Nickell (2005), national pay bargaining may insulate wages from firm idiosyncratic shocks. 
A similar role can be played by the minimum wage legislation, since firms with a large share of their workforce on the minimum wage will have part of their wage policy set by the government based on nationwide trends. Firms that operate in more than one industry or region may be more able to diversify risk. On the contrary, a higher risk of going bankrupt will reduce the firm's possibility to provide wage insurance. We also consider the occupation of the worker, with a dummy variable for managers meant to proxy two factors: the sensitivity of firm output to worker effort, with the wages of crucial workers more closely linked to firm performance, and therefore subject to less insurance provision; the capacity of the worker to bear risk, with managers likely to have more wealth and more access to financial markets where to diversify risk, and larger expertise in financial issues. The possibility of monitoring output has been pointed out as another factor that reduces the degree of insurance provided by the firm. Indeed, if the firm could monitor exactly the effort of the worker, it would not need to engage in a wage contract. Higher precision of the signal on the agent's effort will lead to less insurance. (Guiso et al., 2005, have computed the noise on performance as the variability over time in the performance of the firm.)

The results are reported in Table 6, where Manager is a dummy variable equal to one if the worker is a manager, and Decent.barg. equals one if the worker is covered by firm-level bargaining, as opposed to a massive collective bargaining agreement. ${ }^{7}$ Bankruptcy is the threat of bankruptcy, ${ }^{8}$ NInd is the number of industries in which the firm operates, FSize stands for ( $\log$ of) firm employment, and Foreign is a dummy variable for the foreign origin of the capital; SDsales represents the volatility of firm sales, ${ }^{9}$ and Shareminw is the share of workers in the firm earning the national minimum wage.

To estimate these regressions we once again implemented the GMM procedure used in Panel B of Table 5, and define the extra instruments as the previous instruments interacted with the new variables. The validity of the instruments used is not rejected in both regressions. Since we have multiple endogenous regressors, Shea's (1997) partial $R^{2}$ is reported.

Results indicate that firms with a larger share of their workforce earning the minimum wage are less able to translate permanent shocks in product demand into wage changes. Indeed, the minimum wage is set at the national level by government regulation, taking into explicit account

\footnotetext{
${ }^{7}$ Worker covered by a firm-level agreement or collective bargaining agreement (which involves a restricted group of firms, not organized into an employer association), as opposed to collective bargaining contracts, which often cover a whole industry, or the mandatory regime imposed by the government.

${ }^{8}$ The percentage of firms that go bankrupt in a given year and detailed region.

${ }^{9}$ Measured by the standard deviation of logarithm of sales for the years under analysis.
} 
Table 6. Insurance heterogeneity

\begin{tabular}{lcc}
\hline & Permanent shock & Transitory shock \\
\hline$\Delta \epsilon_{j t}$ & -0.1628 & -0.0506 \\
& $(0.1016)$ & $(0.0076)$ \\
$\Delta \epsilon_{j t} *$ Manager & {$[0.0281]$} & {$[0.3192]$} \\
& 0.0194 & -0.0039 \\
$\Delta \epsilon_{j t} *$ SDSales & $(0.0054)$ & $(0.0029)$ \\
& {$[0.0157]$} & {$[0.4370]$} \\
$\Delta \epsilon_{j t} *$ Bankruptcy & -0.0078 & 0.0023 \\
& $(0.0081)$ & $0.0013)$ \\
$\Delta \epsilon_{j t} *$ Foreign & {$[0.0990]$} & {$[0.4230]$} \\
& 0.0215 & 0.0021 \\
$\Delta \epsilon_{j t} *$ FSize & $(0.0110)$ & $0.0004)$ \\
& {$[0.0298]$} & {$[0.3736]$} \\
$\Delta \epsilon_{j t} *$ NInd & 0.0149 & 0.0124 \\
& $(0.0239)$ & $(0.0023)$ \\
$\Delta \epsilon_{j t} *$ Shareminw & {$[0.0380]$} & {$[0.4229]$} \\
& -0.0050 & 0.0018 \\
$\Delta \epsilon_{j t} *$ Decent.barg. & $(0.0081)$ & $(0.0012)$ \\
& {$[0.0486]$} & {$[0.3717]$} \\
Observations & 0.0101 & 0.0063 \\
$J$-test: $p$-value & $(0.0245)$ & $(0.0041)$ \\
\hline
\end{tabular}

Notes: The dependent variable is $\Delta \omega_{i j t}$. The instruments used in each regression are explained in the text. Robust standard errors reported in parentheses; Shea's (1997) partial $R^{2}$ in square brackets. We account for within-firm correlation of residuals. We report the $J$-test for the validity of the instruments.

aggregate trends such as the overall economy inflation rate. However, when faced with transitory shocks, firms with different shares of minimum wage workers do not react differently in terms of wage insurance. The level at which collective bargaining takes place also has an impact on the degree of insurance provided by the firm when faced with transitory shocks. More decentralized bargaining regimes are associated with less insurance, as opposed to massive collective wage-setting agreements, which constrain the capacity of the firm to reflect demand shocks on wage changes.

Managers are less insured against permanent shocks than the rest of the workforce. This could be due to the fact that they may receive performance pay that links wages directly to the results of the company. Moreover, managers can be expected to be less risk-averse than other workers, and 
as such would not have to be given the same level of insurance to exert effort. However, managers and workers with other occupations receive equal protection against transitory shocks.

Firms with a higher threat of bankruptcy are, as expected, less able to provide wage insurance and more constrained to reflect changes in product markets into changes in wages. That holds both for transitory and permanent shocks. Firms with higher variability in their sales offer less insurance against transitory changes in their performance. When faced with higher uncertainty in product markets, firms in the short run are bound to reflect more of the change in sales on wages. Foreign firms provide less insurance to transitory shocks.

\section{Conclusion}

The impact of product market uncertainty on worker wages has been evaluated, relying on data of remarkable quality to estimate dynamic panel data models. Results point to the rejection of the full insurance hypothesis. Workers' wages respond to permanent shocks on firm performance, whereas they are not sensitive to transitory shocks. In comparison to Italy, Portuguese firms provide less insurance to their workers. The higher responsiveness of wages to shocks at the firm level corroborates evidence previously reported on the high degree of wage flexibility in Portugal, when evaluated as the responsiveness of wages to macroeconomic conditions.

Another aim of the analysis was to check the impact of labor market regulations on the extent to which firms translate idiosyncratic shocks in product markets into shocks to the wages paid. We found that the national minimum wage and collective bargaining are indeed associated with the extent of wage insurance provided by the firm. Firms with a larger share of their workforce earning the minimum wage are less able to translate permanent shocks in product demand into wage changes. Also, massive collective wage-setting agreements constrain the capacity of the firm to reflect idiosyncratic demand shocks into wage changes. This would be consistent with a corporatist wage-setting view of the labor market, according to which the major role of these institutions would be to promote a smooth adjustment of wages to other types of shocks, those at the aggregate level.

\section{Appendix. Longitudinal Linked Employer-Employee Dataset}

\section{Checks on the Consistency of Data}

After merging the worker data across years, inconsistencies were identified if the worker gender or date of birth was reported as changing, or if the highest 
schooling level achieved was reported as decreasing over time. In that case, the information reported over half the times has been taken as the correct one ${ }^{10}(0.8 \%, 2.3 \%$ and $5.2 \%$ of the observations have been corrected, respectively, for gender, birth date and education). Workers with inconsistent data after the introduction of the previous corrections were dropped. All information on the worker was dropped, despite the incorrect number of observations identified $(1.7 \%, 1.1 \%$ and $4.3 \%$ of the observations, respectively, for gender, birth date and schooling). Workers with missing age or schooling after the introduction of the previous corrections were dropped (respectively, $0.7 \%$ and $1.7 \%$ of the observations, corresponding to $2.1 \%$ and $2.0 \%$ of the workers).

\section{Constraints Imposed}

The analysis focuses on workers and firms in the manufacturing and services private sector in mainland Portugal.

On the worker side, we have retained wage earners working full-time, aged 18 to 65 , whose wage is not below the national minimum wage ${ }^{11}$ (which led to dropping $20 \%$, $2 \%$ and $3 \%$ of the dataset, respectively). Outliers in wage growth have been dropped, ${ }^{12}$ which corresponded to a very small share of the database, $0.03 \%$. Workers observed just once in the database cannot be considered in the estimation of the models used (and, thus, 5\% have been dropped). This is the full set of workers, which comprises over 10 million observations. Owing to the large size of the full dataset it was not feasible to run the worker computations on the full dataset and we have therefore used a $2 \%$ random sample of workers (keeping all the yearly observations for the selected workers). Descriptive statistics on this sample, comprising 205,352 yearly observations on 42,008 workers, are presented in Table A1. ${ }^{13}$

On the firm side, we have kept firms operating full-year, and those in which sales are not missing or outlier ${ }^{14}$ (thus dropping $3 \%, 9 \%$ and $0.2 \%$ of the firms, respectively). ${ }^{15}$ Firms that were ever larger than 20 workers have been kept for analysis, since they are more likely to be run in entrepreneurial terms. Given the very small size structure of the firms in the Portuguese economy, this led to keeping $12 \%$ of the firms. The set of firms under analysis comprises 131,118 yearly observations on 18,368 firms. Descriptive statistics are reported in Table A2. ${ }^{16}$

\footnotetext{
${ }^{10}$ Note that this requirement is more demanding than just considering the modal value as the accurate one.

${ }^{11}$ May drop apprentices and handicapped workers.

${ }^{12} \mathrm{Log}$ difference in real wages either greater than 2 or smaller than -0.5 .

${ }^{13}$ The dynamics in the models under estimation determine that a smaller number of individuals will be considered in the regressions.

${ }^{14} \log$ difference in real sales either greater than 5 or smaller than -5 .

${ }^{15}$ Firms in the first few months of their existence, not yet one year, were excluded, to avoid capturing sales fluctuations that are due to part-year operations.

${ }^{16}$ The dynamics in the models under estimation determine that a smaller number of firms will be considered in the regressions.
} 
Table A1. Descriptive statistics on workers

\begin{tabular}{|c|c|c|}
\hline Variable & Mean & Std. dev. \\
\hline Log real monthly wage (PTE) & 11.63 & 0.50 \\
\hline Age & 36.20 & 10.91 \\
\hline Gender (female) & 0.39 & \\
\hline \multicolumn{3}{|l|}{ Education } \\
\hline 4 years & 0.46 & \\
\hline 6 years & 0.22 & \\
\hline 9 years & 0.13 & \\
\hline High school & 0.14 & \\
\hline University & 0.05 & \\
\hline \multicolumn{3}{|l|}{ Occupation } \\
\hline Managers & 0.02 & \\
\hline Professionals & 0.02 & \\
\hline Middle managers, technicians & 0.09 & \\
\hline Administrative & 0.15 & \\
\hline Service, sales & 0.11 & \\
\hline Skilled & 0.27 & \\
\hline Machine operators, assembly & 0.14 & \\
\hline Unskilled & 0.15 & \\
\hline Unknown & 0.05 & \\
\hline \multicolumn{3}{|l|}{ Industry } \\
\hline Food, beverages, tobacco & 0.05 & \\
\hline Textiles & 0.17 & \\
\hline Wood & 0.04 & \\
\hline Chemicals & 0.05 & \\
\hline Mineral products & 0.15 & \\
\hline Construction & 0.10 & \\
\hline Trade & 0.21 & \\
\hline Restaurants, hotels & 0.05 & \\
\hline Transport, communication & 0.04 & \\
\hline Banking, insurance, business services & 0.09 & \\
\hline Other services & 0.05 & \\
\hline \multicolumn{3}{|l|}{ Region } \\
\hline North coast & 0.34 & \\
\hline Center coast & 0.16 & \\
\hline Lisbon & 0.40 & \\
\hline Inland & 0.08 & \\
\hline Algarve & 0.03 & \\
\hline \multicolumn{3}{|l|}{ Type of collective bargaining agreement } \\
\hline Decentralized & 0.06 & \\
\hline Massive & 0.94 & \\
\hline$N$ & \multicolumn{2}{|c|}{205,352} \\
\hline
\end{tabular}

\section{Descriptive Statistics}

Gross monthly earnings were computed as monthw $=b w+s e n+r e g$, where $b w$ stands for base-wage, sen are seniority-indexed components of pay, and reg are other regularly paid components. Wages were deflated using the consumer price index. 
Table A2. Descriptive statistics on firms

\begin{tabular}{lrr}
\hline Variable & Mean & Std. dev. \\
\hline Log real sales (1,000 PTE) & 12.93 & 1.45 \\
Number of workers in firm & 58.22 & 170.80 \\
Number of industries in firm & 1.09 & 0.38 \\
Share firms bankrupt in province & 0.09 & 0.04 \\
Variability firm sales over time: s.d. log real sales & 0.50 & 0.51 \\
Share of workers earning the minimum wage & 0.03 & 0.11 \\
Industry & & \\
Food, beverages, tobacco & 0.05 & \\
Textiles & 0.19 & \\
Wood & 0.05 & \\
Chemicals & 0.06 & \\
Mineral products & 0.15 & \\
Construction & 0.11 & \\
Trade & 0.20 & \\
Restaurants, hotels & 0.04 & \\
Transport, communication & 0.04 & \\
Banking, insurance, business services & 0.06 & \\
Other services & 0.05 & \\
Region & & \\
North coast & & \\
Center coast & 0.34 & \\
Lisbon & 0.18 & \\
Inland & 0.37 & \\
Algarve & 0.08 & \\
Origin of capital & 0.03 & \\
National & & \\
Foreign & & \\
$N$ & 0.94 & \\
\hline
\end{tabular}

\section{References}

Abowd, J. M. and Allain, L. (1996), Compensation Structure and Product Market Competition, Annales d'Économie et de Statistique 41/42, 207-217.

Abowd, J. A. and Lemieux, T. (1993), The Effects of Product Market Competition on Collective Bargaining Agreements: The Case of Foreign Competition in Canada, Quarterly Journal of Economics 108, 983-1014.

Altonji, J. G. and Segal, L. M. (1996), Small-sample Bias in GMM Estimation of Covariance Structures, Journal of Business and Economic Statistics 14, 353-367.

Arellano, M. and Bond, S. (1991), Some Tests of Specification for Panel Data: Monte Carlo Evidence and an Application to Employment Equations, Review of Economic Studies 58, 277-297.

Azariadis, C. (1975), Implicit Contracts and Underemployment Equilibria, Journal of Political Economy 83, 1183-1202.

Baily, M. N. (1974), Wages and Employment under Uncertain Demand, Review of Economic Studies 41, 7-50.

(C) The editors of the Scandinavian Journal of Economics 2009 
Baum, C. F., Schaffer, M. E. and Stillman, S. (2003), Instrumental Variables and GMM: Estimation and Testing, Stata Journal 3, 1-31.

Beaudry, P. and DiNardo, J. (1991), The Effects of Implicit Contracts on the Movement of Wages over the Business Cycle: Evidence from Micro Data, Journal of Political Economy 99, 665-688.

Blanchflower, D. G., Oswald, A. J. and Sanfey, P. (1996), Wages, Profits and Rent-sharing, Quarterly Journal of Economics 111, 227-251.

Blundell, R. and Bond, S. (1998), Initial Conditions and Moment Restrictions in Dynamic Panel Data Models, Journal of Econometrics 87, 115-143.

Cardoso, A. R. (1999), Firm's Wage Policies and the Rise in Labor Market Inequality: The Case of Portugal, Industrial and Labor Relations Review 53, 87-102.

Cardoso, A. R. and Portugal, P. (2005), Contractual Wages and the Wage Cushion under Different Bargaining Settings, Journal of Labor Economics 23, 875-902.

Christofides, L. N. and Oswald, A. J. (1992), Real Wage Determination and Rent-sharing in Collective Bargaining Agreements, Quarterly Journal of Economics 107, 985-1002.

Devereux, P. J. (2005), Do Employers Provide Insurance against Low Frequency Shocks? Industry Employment and Industry Wages, Journal of Labor Economics 23, 313-340.

Estevão, M. and Tevlin, S. (2003), Do Firms Share their Success with Workers? The Response of Wages to Product Market Conditions, Economica 70, 597-617.

Faggio, G. and Nickell, S. (2005), The Responsiveness of Wages to Labour Market Conditions in the UK, Labour Economics 12, 685-696.

Gamber, E. N. (1988), Long-term Risk-sharing Wage Contracts in an Economy Subject to Permanent and Temporary Shocks, Journal of Labor Economics 6, 83-99.

Gordon, D. F. (1974), A Neo-classical Theory of Keynesian Unemployment, Economic Inquiry $12,431-459$.

Guiso, L., Pistaferri, L. and Schivardi, F. (2005), Insurance within the Firm, Journal of Political Economy 113, 1054-1087.

Harris, M. and Holmstrom, B. (1982), A Theory of Wage Dynamics, Review of Economic Studies 49, 315-333.

Hildreth, A. K. G. and Oswald, A. J. (1997), Rent-sharing and Wages: Evidence from Company and Establishment Panels, Journal of Labor Economics 15, 318-337.

Holmstrom, B. (1981), Contractual Models of the Labor Market, American Economic Review $71,308-313$.

Holzer, H. J. and Montgomery, E. B. (1993), Asymmetries and Rigidities in Wage Adjustments by Firms, Review of Economics and Statistics 75, 397-408.

Kramarz, F. (2003), Wages and International Trade, CEPR Discussion Paper no. 3936, London.

Nickell, S. and Wadhwani, S. (1990), Insider Forces and Wage Determination, Economic Journal 100, 496-509.

OECD (Organisation for Economic Co-operation and Development) (1992), OECD Economic Surveys, Portugal, 1991/92, OECD, Paris.

OECD (Organisation for Economic Co-operation and Development) (1994), OECD Employment Outloook 1994, OECD, Paris.

OECD (Organisation for Economic Co-operation and Development) (1999), OECD Employment Outlook 1999, OECD, Paris.

Portugal, Ministério do Trabalho e da Segurança Social (1986 to 1999), Quadros de Pessoal, data in magnetic media.

Rosen, S. (1985), Implicit Contracts: A Survey, Journal of Economic Literature 23, 1144 1175 .

Shea, J. (1997), Instrument Relevance in Multivariate Linear Models: A Simple Measure, Review of Economics and Statistics 79, 348-352. 
Teulings, C. N. (1997), A New Theory of Corporatism and Wage Setting, European Economic Review 41, 659-669.

Thomas, J. and Worrall, T. (1988), Self-enforcing Wage Contracts, Review of Economic Studies 55, 541-553.

Weinberg, B. (2001), Long-term Wage Fluctuations with Industry-specific Human Capital, Journal of Labor Economics 19, 231-264.

Weiss, Y. (1984), Wage Contracts when Output Grows Stochastically: The Roles of Mobility Costs and Capital Market Imperfections, Journal of Labor Economics 2, 155-173.

First version submitted November 2006;

final version received June 2008. 